\title{
Sensitivity of simulated cyclone Gonu intensity and track to variety of parameterizations: Advanced hurricane WRF model application
}

\author{
M Alimohammadi and H Malakooti* \\ Department of Marine Science and Technology, University of Hormozgan, Bandar Abbas, Iran. \\ *Corresponding author. e-mail: malakooti@hormozgan.ac.ir
}

MS received 1 August 2016; revised 15 June 2017; accepted 8 August 2017; published online 6 April 2018

Domain configuration and several physical parameterization settings such as planetary boundary layer, cumulus convection, and ocean-atmosphere surface flux parameterizations can play significant roles in numerical prediction of tropical cyclones. The present study focuses to improve the prediction of the TC Gonu by investigating the sensitivity of simulations to mentioned configurations with the Advanced Hurricane WRF model. The experiments for domain design sensitivity with $27 \mathrm{~km}$ resolution has been shown moving the domains towards the east improve the results, due to better account for the large-scale process. The fixed and movable nests on a $9-\mathrm{km}$ grid were considered separately within the coarse domain and their results showed that despite salient improvement in simulated intensity, an accuracy reduction in simulated track was observed. Increasing horizontal resolution to $3 \mathrm{~km}$ incredibly reduced the simulated intensity accuracy when compared to $27 \mathrm{~km}$ resolution. Thereafter, different initial conditions were experimented and the results have shown that the cyclone of $1000 \mathrm{hPa}$ sea level pressure is the best simulation initial condition in predicting the track and intensity for cyclone Gonu. The sensitivity of simulations to ocean-atmosphere surface-flux parameterizations on a 9-km grid showed the combination of 'Donelan scheme' for momentum exchanges along with 'Large and Pond scheme' for heat and moisture exchanges provide the best prediction for cyclone Gonu intensity. The combination of YSU and MYJ PBL scheme with KF convection for prediction of track and the combination of YSU PBL scheme with KF convection for prediction of intensity are found to have better performance than the other combinations. These 22 sensitivity experiments also implicitly lead us to the conclusion that each particular forecast aspect of TC (e.g., track, intensity, etc.) will require its own special design.

Keywords. Tropical cyclone; Gonu; surface fluxes; PBL; cumulus convection; AHW.

\section{Introduction}

Tropical cyclones (TCs), due to their nature, are recognized as the most common and devastating of all natural disasters. The improvement of TCs track and intensity prediction can significantly help in reducing loss of life and property. The previous studies show that the numerical forecast using dynamical models can provide better TCs track and intensity prediction as compared to synoptic and statistical methods (Mohanty and Gupta 1997; Rao and Bhaskar Rao 
2003; Mandal et al. 2004; Osuri et al. 2012). Nearly $80-90 \%$ of TCs attain intensity of $33 \mathrm{~m} / \mathrm{s}$ (Frank and George 2007). Among all TCs, about 7\% occur in the north Indian Ocean (NIO), including the Arabian Sea (AS) and the Bay of Bengal (BoB), and about $2 \%$ of all TCs have their origin in AS (World Meteorological Organization (WMO) technical report 2014). Even though the period of occurrence of TCs in AS is lower than any other region of the world, the inadequate prediction of TCs over this region had caused extensive devastation (e.g., cyclone Gonu). When we review the recent studies on the simulation of the TCs over NIO, it is clear that simulation of Gonu is more problematic compared with other TCs. The results of Osuri et al. (2012) using WRF(ARW) show the best of peak intensity predicted for Gonu (one of five selective cases) was $35 \mathrm{~m} / \mathrm{s}$ that there is salient difference about $30 \mathrm{~m} / \mathrm{s}$ than India Meteorological Department (IMD) reference data as well as the trend of evolution of intensity is not captured and while the track predicted was rather satisfactory, but the model could not predict the first landfall over Oman. Osuri et al. (2013) presented the satisfactory performance of the WRF(ARW) model based on the 100 forecasts for 17 TCs over NIO; however, the prediction of Gonu (one of 17 selective cases) was a problem where the model predicted the first landfall over Oman with some southward displacement while the model could not predict the second landfall of Gonu over Iran. The best of peak intensity predicted for Gonu was $48 \mathrm{~m} / \mathrm{s}$ which has a difference of about $17 \mathrm{~m} / \mathrm{s}$ than IMD reference data. The results of Mohandas and Ashrit (2013) show the simulation of Gonu (one of three selective cases) using WRF(NMM) for the intensity, was underpredicted as well as the track was not satisfactory. We can add the studies of Deshpande et al. (2010) using MM5, Pattanayak and Mohanty (2008) used WRF and MM5 to abovementioned configurations. In this study, we intend to improve the prediction of the TC Gonu using the Advanced Hurricane WRF(AHW) model. Kumar et al. (2011) used AHW model over NIO for the first time, to simulate the cyclone Sidr (2007, Bay of Bengal) which improved previous results of the cyclone. They presented the selective domains which had major impact on the simulations of TCs. The results of Kumar et al. (2011) also suggested that the cyclone track is controlled by large-scale features such as synoptic winds while intensity strongly depends on both local and large-scale conditions. Kanase and Salvekar (2011) investigated the sensitivity of the TC Laila simulations to initial conditions. Their results show the simulations dependent on the initial condition and simulated results are improved when the initial conditions are applied prior to the formation of low. The results of Kumar et al. (2011) prove the findings of Kanase and Salvekar (2011). Among all of the physical parameterizations, PBL and convection have long been recognized as processes of central importance in the genesis and intensification of TCs (Osuri et al. 2012). The PBL is a critical factor (Braun and Tao 2000) because of generation of the large fluxes of heat, moisture, and momentum in this thin layer (Osuri et al. 2012). Davis et al. (2010) presented that intensity (maximum wind) and rapid intensification, as well as wind radii, were all predicted more accurately with increased horizontal resolution.

In addition, the designation of surface-flux parameterizations, including momentum due to surface waves, especially in high wind conditions and enthalpy (heat and moisture) between ocean and atmosphere are significant in the accuracy of results. It plays an important role in the prediction of TCs intensity over the ocean surface and finally, the cooling effect of the ocean mixed layer could be a key issue in the prediction of cyclone intensity (Davis et al. 2008).

One of the new contributions of this study is the implementation of sensitivity analysis for selective domains. By taking the route of TCs over the AS to west-northwest-southwestwards, and impact of the large-scale process (especially easterly winds) in TCs track, optimum domain design is of particular importance at the prediction of TCs intensity and track in this area. One key question, what is the appropriate time to start the simulation according to the TC life cycle? We carried out a sensitivity analysis with an initial condition to answer this question for the AS region. The proper functioning of physical parameterizations consist of cumulus convection, surface fluxes of heat, moisture, momentum, and vertical mixing in PBL will lead us to better predict TCs intensity and track in this region.

The sensitivity of the TC Gonu simulations to domain configuration (coverage, resolution and nesting), initial condition, ocean-atmosphere surface flux parameterizations (momentum, heat and moisture), planetary boundary layer (PBL) and cumulus convection physical parameterizations 

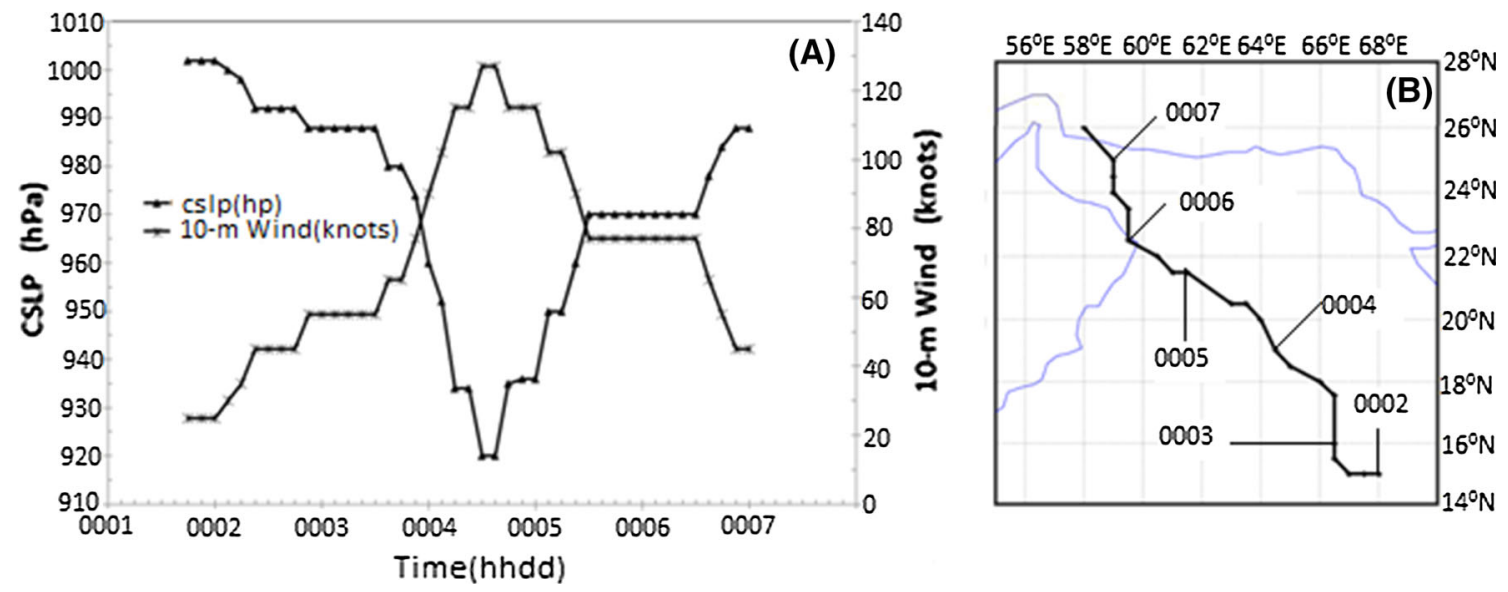

Figure 1. The information of reference track for cyclone Gonu received from IMD. (a) CSLP and maximum 10-m wind and (b) IMD reference track.

were investigated with the AHW model to improve the prediction of the TC Gonu.

\section{Data}

Supercyclone Gonu, equivalent to Category 5 on the Saffir-Simpson scale, was one of the strongest tropical cyclones ever recorded which was formed in the Arabian Sea during the period of 1-7 June, 2007. At the peak intensity, Gonu caused 3-min sustained wind of about $240 \mathrm{~km} / \mathrm{hr}$ and minimum pressure of about $920 \mathrm{hPa}$. Around 4.2 billion USD of financial losses and 78 human casualties were caused by cyclone Gonu (India Meteorological Department Report 2008).

Herein, we do not plan to explore the synoptic conditions of the cyclone Gonu formation. The performance of AHW model is evaluated in explicit simulations of supercyclone, Gonu.

The AHW is a relatively new derivative of the WRF(ARW) model that was initially developed from the community release of the WRF model after 2005 (Davis et al. 2008). Vortex following inner domain, 2-way nested grid system, implementation of some complemental surface fluxes parameterizations and utilities such as TC Bogus scheme (vortex replacement strategy in the initialization fields), made AHW ideal for the prediction of the multiple length scales present in hurricanes ranging from synoptic scale (1000 $\mathrm{km}$ or more) to the sharp gradients inside the eye wall (5$10 \mathrm{~km})$. In AHW model, 1D Ocean mixed-layer model based on Pollard et al. (1973) was added to WRF to provide a feedback of mixing-induced sea-surface cooling to the atmosphere and forecasts were extended to 5 days.
The AHW is distinct from the Hurricane WRF (HWRF) developed by National Centers for Environmental Prediction (NCEP). HWRF is based on the NMM (non-hydrostatic mesoscale model) dynamic core of the WRF with ocean model coupling (Princeton Ocean Model) and physical GFDL surface parameterization. The HWRF does not provide operational real time forecast over NIO; however, it gives real-time experimental forecasts for NIO regions (see Gopalakrishnan et al. 2010; Tallapragada et al. 2014).

The diversity of surface parameterization accompanied with air-sea coupling (1D ocean mixed-layer model) is introduced in AHW. Convenience in model initialization and also its good performance in recent studies (e.g., Torn 2016; Davis et al. 2008) have motivated authors to conduct the variety of the sensitivities explained in section 3 with AHW model.

The data from NCEP global final analysis (FNL) on a $1.0^{\circ} \times 1.0^{\circ}$ grid was used to provide initial and boundary conditions for numerical simulations. Sea surface temperatures were derived from the highresolution real-time global sea surface temperature (RTG_SST) at 1/12-degree resolution analyses dataset from NCEP Marine Modeling and Analysis Branch (MMAB). The information of cyclone Gonu reference track with $3 \mathrm{~h}$ resolution during $18 \mathrm{UTC}$ 1 June-03 UTC 7 June 2007 has been received from IMD (figure 1). The tropical storm Gonu was developed as a depression over the east-central Arabian Sea with centre near $15.0^{\circ} \mathrm{N}, 68.0^{\circ} \mathrm{E}$ at 18 UTC 1 June 2007. It moved northwestward and intensified into a severe cyclonic storm with central pressure of $988 \mathrm{hPa}$, centred at $15.5^{\circ} \mathrm{N}, 66.5^{\circ} \mathrm{E}$. The system moved west-northwestwards and further intensified as a supercyclonic storm and laid 


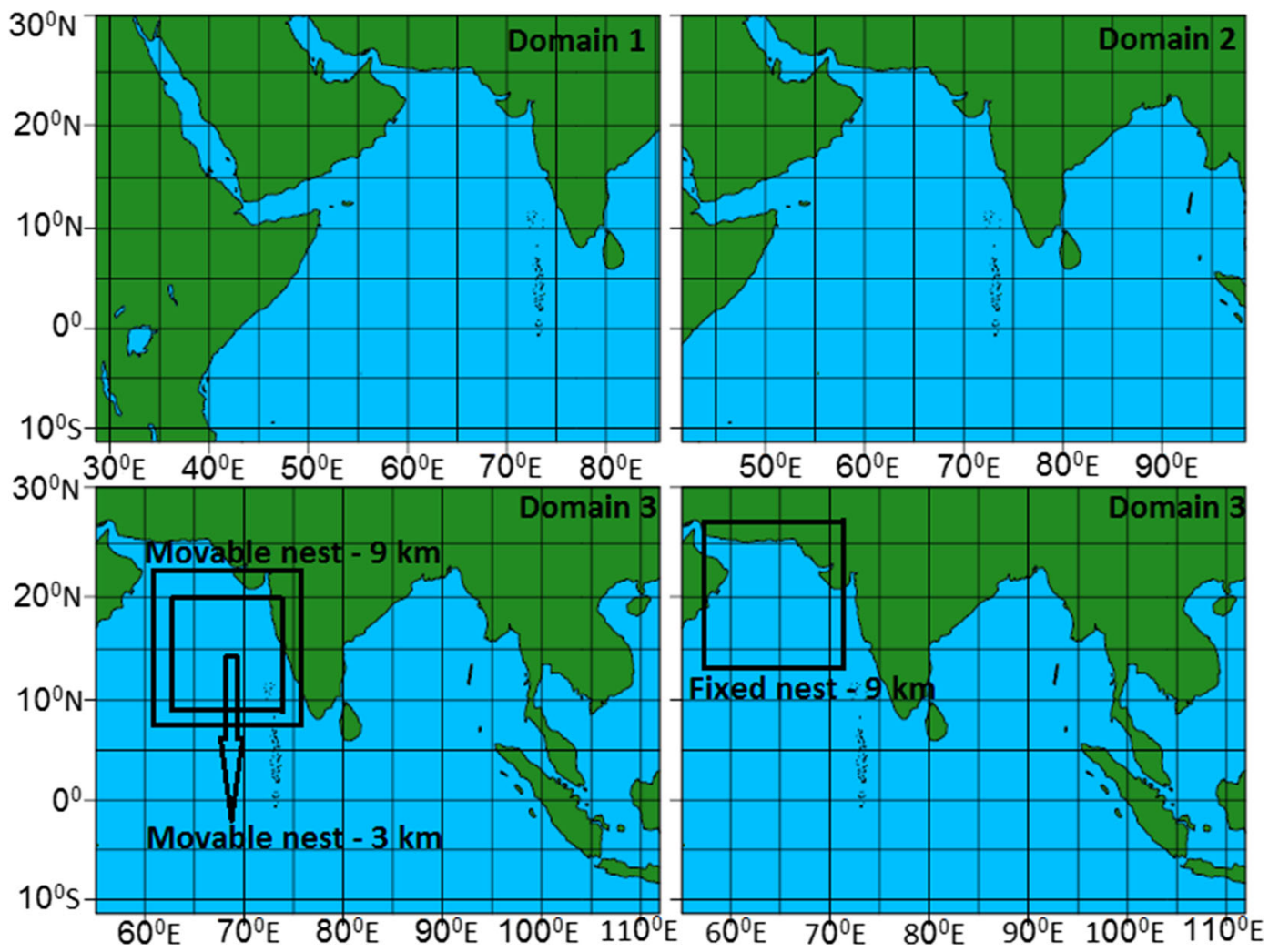

Figure 2. Selective domains for sensitivity experiments with model domain coverage, nesting and horizontal resolution.

its centre at $20.0^{\circ} \mathrm{N}, 64.0^{\circ} \mathrm{E}$, with minimum central pressure of $920 \mathrm{hPa}$ and maximum surface wind of 127 knots. Then the storm moved further in the northwestward direction and weakened and laid its centre over northwest Arabian Sea at $20.5^{\circ} \mathrm{N}$, $63.5^{\circ} \mathrm{E}$, with minimum central pressure of $935 \mathrm{hPa}$. Then it gradually weakened, moved northwestward and crossed northeast Oman coast near Muscat in $22.5^{\circ} \mathrm{N}, 59.0^{\circ} \mathrm{E}$ with minimum central pressure of $970 \mathrm{hPa}$ during 02-03 UTC of 6 June and crossed the Makran (Iran) coast near $25.0^{\circ} \mathrm{N}, 58.0^{\circ} \mathrm{E}$ with minimum central pressure of $988 \mathrm{hPa}$ during 03-04 UTC 7 June 2007 as a cyclonic storm.

The coupled mixed layer ocean model with WRF model requires specification of an initial mixed layer depth $h_{0}$ and a deep-layer lapse rate $\Gamma$. The ocean model was initialized with $h_{0}$ and $\Gamma$ equal to $50 \mathrm{~m}$ and $0.14 \mathrm{k} / \mathrm{m}$, respectively in order to consider negative feedback of wind-driven ocean mixing on cyclone intensity (Davis et al. 2008).

\section{Methodology}

We considered separately three individual domains in horizontal resolution of $27 \mathrm{~km} .145 \times 110$ grid points were taken in the $\mathrm{x}$ and $\mathrm{y}$ axes for domains
D1, D2 and D3, while the centers of these three domains are located in latitude $10^{\circ} 00^{\prime}$, but at different longitudes of $57^{\circ} 00^{\prime}, 70^{\circ} 00^{\prime}$ and $83^{\circ} 30^{\prime}$, respectively (figure 2). It is noteworthy that after several tests in horizontal resolution of $27 \mathrm{~km}$ and based on the importance of location of domains (Kumar et al. 2011) in the simulations of TCs, we changed the first three domains towards the east until taking large-scale processes that lead the Gonu track (tables 1, 2 and figure 2) introduce the coordinates, features and configurations of the selective domains and simulations. For the third domain, we also considered fixed nest $(109 \times 109$ grid points) and movable nest $(109 \times 109$ grid points) at the resolution of $9 \mathrm{~km}$ to test the sensitivity of the simulations to horizontal resolution and nesting. Again, the horizontal resolution was improved to $3 \mathrm{~km}$ for achieving another movable nest $(247 \times 247$ grid points $)$ as second inner domain within D3 (figure 2). The fourth, fifth, sixth and seventh simulations were performed on these nests. The first seven simulations were initialized at 00 UTC 2 June for 6 days. The eighth and ninth simulations were performed on the D3 domain to test the sensitivity of the simulations at initial condition. The ninth simulation was initialized at 00 UTC 3 June 2007 and the tenth 
Table 1. Overview of the default AHW model configuration.

\begin{tabular}{ll}
\hline Model & \multicolumn{1}{c}{ AHW } \\
\hline Time integration scheme & 3rd order Runga-Kutta scheme \\
Spatial differencing scheme & 6th order center differencing \\
Micro physics & WSM 6 (Hong et al. 2004 ) \\
Long wave radiation scheme & RRTM (Mlawer et al. 1997) \\
Short wave radiation scheme & Dudhia (1989) \\
Surface layer parameterization & Thermal diffusion scheme \\
Planetary boundary layer physics & YSU (Noh et al. 2003) \\
Cumulus scheme & Kain-Fritsch (Kain 2004) \\
Boundary-initial conditions & NCEP FNL (Global analysis) \\
Surface drag exchange parameterization & Donelan et al. (2004) \\
Surface enthalpy exchange parameterization & Large and Pond (1981) \\
Ocean mixed layer depth & $40 \mathrm{~m}$ \\
Ocean mixed layer lapse rate & $0.14 \mathrm{k} / \mathrm{m}$ \\
Vertical resolution & 37 levels \\
Model top & 2000 Pa \\
\hline
\end{tabular}

Table 2. Differences of AHW model configuration for all defined experiments.

\begin{tabular}{|c|c|c|c|}
\hline Names of experiments & Horizontal resolution & Domain coverage & Center-point \\
\hline 27 km-D1 & $27 \mathrm{~km}$ & $\mathrm{D} 1,11,442,384 \mathrm{~km}^{2}$ & $10^{\circ} 00^{\prime} \mathrm{N}, 5700 / \mathrm{E}$ \\
\hline $27 \mathrm{~km}-\mathrm{D} 2$ & $27 \mathrm{~km}$ & $\mathrm{D} 2,11,627,550 \mathrm{~km}^{2}$ & $10^{\circ} 00^{\prime} \mathrm{N}, 7000 / \mathrm{E}$ \\
\hline \multirow[t]{2}{*}{$27 \mathrm{~km}-\mathrm{D} 3$} & $27 \mathrm{~km}$ & D3, $11,627,550 \mathrm{~km}^{2}$ & $10^{\circ} 00^{\prime} \mathrm{N}, 8330 / \mathrm{E}$ \\
\hline & Horizontal resolution & Domain coverage & Nesting \\
\hline $9 \mathrm{~km}$-fixed nesting & $9 \mathrm{~km}$ & $944,784 \mathrm{~km}^{2}$ & Fixed nesting within D3 \\
\hline 9 km-movable nesting & $9 \mathrm{~km}$ & $944,784 \mathrm{~km}^{2}$ & Fixed nesting within D3 \\
\hline $3 \mathrm{~km}$-movable nesting-cu 0 & $3 \mathrm{~km}$ & $544,644 \mathrm{~km}^{2}$ & Fixed nesting within D3 \\
\hline \multirow[t]{2}{*}{$3 \mathrm{~km}$-movable nesting-cu 1} & $3 \mathrm{~km}$ & $544,644 \mathrm{~km}^{2}$ & Fixed nesting within D3 \\
\hline & Horizontal resolution & Initial condition & Duration \\
\hline 27 km-2 June-6 days & $27 \mathrm{~km}$ & 02 June 2007: 00 UTC & 6 days \\
\hline 27 km-3 June-5 days & $27 \mathrm{~km}$ & 03 June 2007: 00 UTC & 5 days \\
\hline \multirow[t]{2}{*}{27 km-4 June- 4 days } & $27 \mathrm{~km}$ & 04 June 2007: 00 UTC & 4 days \\
\hline & Horizontal resolution & $C_{d}$ parameterization & $C_{k}$ parameterization \\
\hline 27 km-Charnock-Carlson and Boland & $27 \mathrm{~km}$ & Charnock & Carlson and Boland \\
\hline 27 km-Donelan-Large and Pond & $27 \mathrm{~km}$ & Donelan & Large and Pond \\
\hline 27 km-Donelan-Garratt & $27 \mathrm{~km}$ & Donelan & Garratt \\
\hline $9 \mathrm{~km}$-Charnock-Carlson and Boland & $9 \mathrm{~km}$ & Charnock & Carlson and Boland \\
\hline $9 \mathrm{~km}$-Donelan-Large and Pond & $9 \mathrm{~km}$ & Donelan & Large and Pond \\
\hline \multirow[t]{2}{*}{9 km-Donelan-Garratt } & $9 \mathrm{~km}$ & Donelan & Garratt \\
\hline & Horizontal resolution & PBL scheme & Convection scheme \\
\hline 9 km-YSU-BMJ & $9 \mathrm{~km}$ & YSU & BMJ \\
\hline 9 km-YSU-KF & $9 \mathrm{~km}$ & YSU & $\mathrm{KF}$ \\
\hline 9 km-YSU-no & $9 \mathrm{~km}$ & YSU & No cumulus \\
\hline 9 km-MYJ-BMJ & $9 \mathrm{~km}$ & MYJ & BMJ \\
\hline 9 km-MYJ-KF & $9 \mathrm{~km}$ & MYJ & $\mathrm{KF}$ \\
\hline 9 km-MYJ-no & $9 \mathrm{~km}$ & MYJ & No cumulus \\
\hline
\end{tabular}


simulation was initialized at 00 UTC 4 June 2007. The first nine simulations were performed using physical parameterization schemes as the default configuration which were defined by Kumar et al. (2011) for his simulations (table 1). Cumulus convection, surface fluxes of heat, moisture, momentum and vertical mixing in the PBL play important roles in the development of tropical cyclones (Anthes 1982). The surface-flux parameterizations include both momentum and enthalpy (heat and moisture) exchanges. Two main parameterization schemes for momentum exchange were presented by Charnock (1955) and Donelan et al. (2004), and out of these two, Charnock formulation is a default scheme in mesoscale meteorological models (Krishnamurti 2005). In the Charnock relation, 10-m drag coefficient $\left(C_{d}\right)$ generally increases from about $0.001-0.003$ at normal TC wind strengths and it can increase to 0.005 for category 5 storms (wind $>70 \mathrm{~m} \mathrm{~s}^{-1}$ ). However, in recent field observations (e.g., Black et al. 2007) and laboratory experiments of Donelan et al. (2004), reported a general consensus that $C_{d}$ reaches a maximum near 0.003 at hurricane wind speeds $\left(30-40 \mathrm{~m} \mathrm{~s}^{-1}\right)$, then stops with increasing wind speed. In the Donelan relation, $C_{d}$ is lower than those from the Charnock relation for low winds with a linear increase up to a maximum near 0.0024 at high wind speeds. The ratio of the exchange coefficient of enthalpy $\left(C_{k}\right)$ to $C_{d}$ is introduced as an important factor in TC intensity (Emanuel 1995; Braun and Tao 2000; Davis et al. 2008). Three main parameterizations schemes for enthalpy (heat and moisture) exchange were presented by Carlson and Boland (1978), Large and Pond (1981) and Garratt (1992). The ratio of $C_{k}$ to $C_{d}$ is introduced as an important factor in TC intensity (Emanuel 1995; Braun and Tao 2000; Davis et al. 2008). The $C_{k}$ will increase slowly in Carlson and Boland relation; stay steady in Large and Pond relation and decrease in Garratt relation with increasing wind speed. For this sensitivity experiments, six simulations were performed with the various configurations for surface flux parameterizations on two horizontal grid resolutions $(27 \mathrm{~km}$ on the third domain and $9 \mathrm{~km}$ on movable nest). The names and specifications of these six simulations are given in table 2. To determine the sensitivity of the simulation to PBL and cumulus convection parameterization schemes, we considered the Yonsei University (YSU, Hong et al. 2006) PBL scheme and Mellor-YamadaJanjic (MYJ: Mellor and Yamada 1982; Janjic 2003) PBL scheme and also the Kain (2004), Kain and Fritsch (1993) convection scheme (KF) and Betts Miller and Janjic (Betts and Miller 1986; Janjic 1994) convection scheme (BMJ). The results of previous studies on evaluation of PBL parameterizations and customization of WRF-ARW model for the simulation of tropical cyclones had shown good performance of YSU and MYJ PBL schemes for this purpose (e.g., Nolan et al. 2009; Osuri et al. 2012; Srinivas et al. 2013; Chen et al. 2015). Osuri et al. (2012) and Srinivas et al. (2013) were conducted sensitivity experiments with PBL and convection Parameterizations using WRF (ARW) for several severe tropical cyclones formed over NIO and they found the combination of YSU PBL scheme with KF convection scheme (YKF) provides a better prediction of intensity, track, among the other combinations of physical parameterization schemes (YSU and MYJ PBL Schemes and $\mathrm{KF}, \mathrm{BM}$, and GD convection schemes).

The authors, based on previous studies in this regard, designed their sensitivity experiments with PBL and convection parameterizations using AHW model for Gonu super cyclone. The YSU (Hong et al. 2006) PBL scheme is known as first-order closure scheme, since it does not require any additional prognostic equations to express the effects of turbulence on mean variables. The YSU scheme takes into account non-local mixing by adding a non-local gradient adjustment term $\left(\gamma_{c}\right)$ to the local gradient of each prognostic mean variable for heat and momentum components.

The MYJ PBL scheme is known as TKE closure (1.5 order closure) scheme. The MYJ PBL scheme applies the local mixing with the local diffusivity from the lowest to the highest vertical level for both convective and stable PBL, and there is no separation between the PBL and the free atmosphere mixing. This PBL parameterization method is explained in more detail in Janjic (1990), Mellor and Yamada (1982) and Janjic (2003) (MYJ).

The Kain (2004), Kain and Fritsch (1993) scheme (KF) uses a mass-conserving, one dimensional entraining-detraining plume model that parameterizes updrafts as well as downdrafts. Mixing was allowed at all vertical levels through entrainment and detrainment. This scheme removes convective available potential energy (CAPE) through vertical reorganization of mass at each grid point. The scheme consists of a convective trigger function (based on grid-resolved vertical velocity), a mass-flux formulation, and closure assumptions (Osuri et al. 2012). Betts, Miller and Janjic (Betts and Miller 1986; Janjic 1994) scheme (BMJ) is 
an adjustment-type scheme that forces soundings at each point towards a reference profile of temperature and specific humidity. The scheme's structure favours activation in cases with substantial amounts of moisture in low and mid-levels and positive CAPE. The representation is accomplished by constraining the temperature and moisture fields by the convective cloud field (Osuri et al. 2012). The configurations and specifications of six simulations that were performed with the different combinations of PBL and convection schemes are given in table 2 .

\section{Results and discussion}

\subsection{Sensitivity experiments with model domain coverage}

Figures 3(a), 4(a) and 5(a) show simulated tracks, maximum $10-\mathrm{m}$ wind and minimum sea level pressure, respectively for domains D1, D2 and D3. The domain D1 covers the greater land area. At first glance, it seems this might cause the differences in the simulation of the cyclone track and intensity. As shown in these sensitivity experiments, the domain D3 had the best performance in the simulation of the cyclone track and intensity; however, the second domain could not perform at par to the third domain. Thus, it can be concluded that taking larger amounts of land or sea in domain coverage cannot be considered as a main logical reason for differences in performances. Land cover and large-scale processes play a major role in the prediction of cyclone intensity and track. Kumar et al. (2011) confirmed the importance of the location of domain and presented that the western boundary play a significant role in controlling the track Sidr (2007, Bay of Bengal) TC. By taking the route of TC Gonu to northwest and impact of the largescale process (easterly winds) in the track, and moving the domains towards the east, the results improved. In domain D3, the model predicted the first landfall over Oman with only position error $9 \mathrm{~km}$ and time error $15 \mathrm{hr}$ (delay) and the second landfall of Gonu over Iran with position error $90 \mathrm{~km}$ and time error $15 \mathrm{hr}$ (delay) compared with IMD. The model predicted peak intensity for Gonu of about $50 \mathrm{~m} / \mathrm{s}$ with time error of $15 \mathrm{hr}$ (delay) with a difference of about $15 \mathrm{~m} / \mathrm{s}$ than the IMD reference data. The track simulation of domain D3 had the best performance and the intensity simulation results at the time of the cyclone reaching to the coast of Oman and Iran, were close to IMD. Even though domain 3 predicted best results for peak intensity, the scope of improvement cannot be negated. To achieve the improvement, sensitivity of the simulations to resolution is conducted with fixed and movable nests separately within this domain (domain D3).

\subsection{Sensitivity experiments with horizontal resolution}

Fixed and movable nesting within the domain D3 were conducted with $9 \mathrm{~km}$ resolution separately in fourth and fifth simulations. A dramatic improvement in results was observed for cyclone peak intensity that model predicted $61 \mathrm{~m} / \mathrm{s}$ with time error $12 \mathrm{hr}$ (delay) with $4 \mathrm{~m} / \mathrm{s}$ difference as compared to IMD reference data (see figures $4 \mathrm{~b}$ and $5 \mathrm{~b}$ ). The results are in concordant with the results reported by Davis et al. (2010), but the quality of the predicted track, especially when reaching to Oman as compared to the third simulation (domain D3 with $27 \mathrm{~km}$ horizontal resolution) had been reduced (see figure $3 \mathrm{~b}$ ). Model predicted the first landfall over Oman with position error $100 \mathrm{~km}$ and without any time error and the second landfall of Gonu over Iran almost without position error and with time error of $21 \mathrm{~h}$ (delay) for fixed nesting that had better performance for the track simulation than movable nesting. On third movable nest ( $3 \mathrm{~km}$ resolution), it performed two experiments, one with KF cumulus parameterization and other, without it. The removal of cumulus parameterization is based on the results of Davis et al. (2010) as the grid spacing decreases from around $10-4 \mathrm{~km}$ or less. Poor simulation results of Gonu track in this resolution were predictable according to recent studies (e.g., Goerss 2006), but simulation results of Gonu intensity also incredibly produced higher error-rate compared with reference $9 \mathrm{~km}$ simulation (9-km Movable Nesting) even compared with experiments on $27 \mathrm{~km}$ resolution. We examined numerous domains in different sizes in order to improve $3 \mathrm{~km}$ resolution nest results, but there were no significant improvement in simulated intensity. This result shows that improvement of horizontal and vertical resolution does not always improved simulated TC intensity (Schwartz et al. 2009).

It is worthwhile to mention, global and regional simulations have proved that high resolution is not a requirement for improved track prediction (Goerss 2006). 

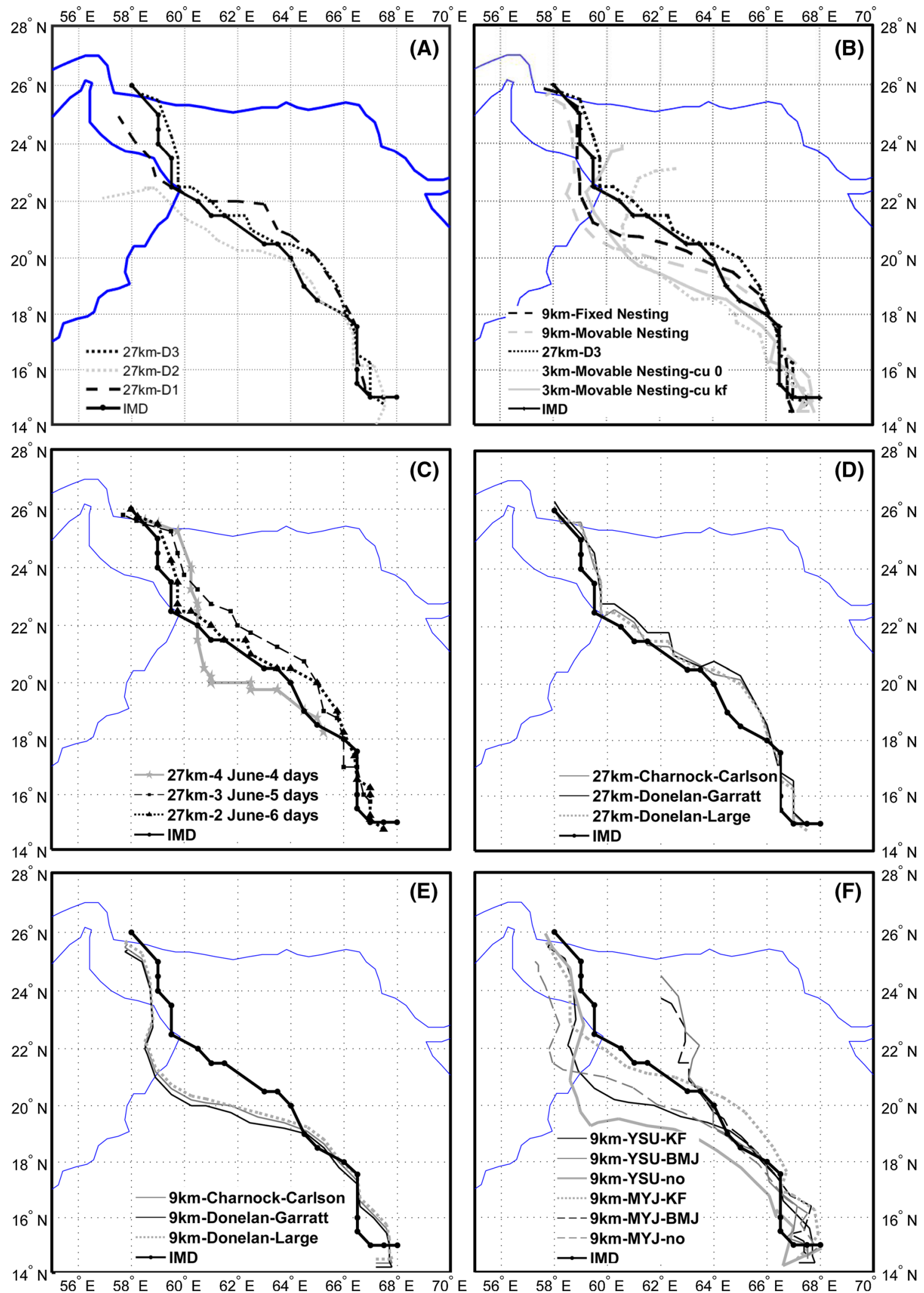

Figure 3. Simulated tracks for different sensitivity experiments. (a) Domain coverage, (b) horizontal resolution, (c) initial condition, (d) surface-fluxes parameterization on 27-km resolution, (e) surface-fluxes parameterization on 9-km resolution, and (f) PBL and convection schemes. 


\subsection{Sensitivity experiments with initial condition}

The eighth and ninth simulations were initialized at 00 UTC 3rd June and 00 UTC 4th June with 5 and 4 days simulation length, respectively. The simulation results were compared with third simulation that had been initialized at 0000 UTC 2 June with 6 days simulation length. IMD reference data for cyclone Gonu shows values of 998, 990 and $980 \mathrm{hPa}$ for the central pressure at 0000 UTC 02 June, 03 June and 04 June, respectively. As can be seen in figures 3(c), 4(c) and 5(c), whatever the initial condition of simulation be, near to peak intensity time of the cyclone, simulated peak intensity of the cyclone have been very weak as well as the simulated track that did not reach to the coast of Oman and with large differences reach on the southeast coast of Iran. This can be, as an important result that the initial condition of simulation must be prior to formation of low or at a point when the central pressure of the cyclone is experiencing almost $1000 \mathrm{hPa}$. This factor can directly affect the amount of water vapour available for latent heat release and storm intensification and allow the initial spin-up of cyclone (Davis and Bosart 2001). This result is comparable with Kumar et al. (2011) and Kanase and Salvekar (2011).

\subsection{Sensitivity experiments with surface-fluxes parameterization}

The results of simulated intensity for coarse domain with $27-\mathrm{km}$ resolution and three surface-flux parameterizations during 00 UTC 02-08 June 2007 are represented in figures $4(\mathrm{~d})$ and $5(\mathrm{~d})$. The comparison of the Donelan-Large and Pond formulation, with less drag and steady $C_{k}$ and the Charnock-Carlson and Boland formulation that have higher drag and increasing $C_{k}$ with wind speed had shown that the former has higher wind speeds as well as lower central pressures. The result was obtained after 48-hr simulation, where wind speed was increased up to 78-knot and higher $C_{d}$ in the Charnock-Carlson and Boland formulation cease increasing speed. With a bit of leniency, we can conclude that the effect of $C_{d}$ numerical value is more than $C_{k}$ in predicting TC intensity. The Donelan-Large and Pond formulation and Donelan-Garratt formulation simulated results with the same drag but different $C_{k}$ in this interval indicated that where $C_{k}$ in DonelanGarratt formulation decreasing with wind speed showed lower wind speeds as well as higher central pressures. It is noteworthy, considering the result of Emanuel (1995) for modelling prediction that the ratio of $C_{k}$ to $C_{d}$ in real TC lies in the range of 0.75-1.5. Davis et al. (2008) suggested that it must be pointed out that the real drag force on surface winds is determined by the time-evolving ocean wave spectrum, prediction of which requires a wave model (e.g., Chen et al. 2007). Therefore; the above-mentioned drag parameterizations should be considered as crude representations of the bulk effects of waves in TCs (Davis et al. 2008). The comparison of the sensitivity of simulated Gonu intensity with various surface-flux parameterizations clearly revealed that the Donelan-Large and Pond configuration have achieved significantly better simulated results on resolution $27-\mathrm{km}$ grid but predicted for cyclone peak intensity with 30knot wind speed was less compared with IMD. Then, it was conducted three simulations on resolution $9-\mathrm{km}$ grid. On this resolution, the results are similar to sensitivities on the $27-\mathrm{km}$ resolution, but it significantly improved the wind speed at the peak intensity as well as Davis et al. (2008) based on sensitivity simulations of Katrina. It means that the Donelan formulation, with less drag than the Charnock formulation, results higher wind speeds but also higher central pressures on $1.33 \mathrm{~km}$ resolution (figures 4e and 5e). Figure 5(e) exhibits that the central pressure simulated by CharnockCarlson and Boland formulation is lower than Donelan-Large and Pond formulation. The results of simulated tracks did not demonstrate significant sensitivity to these surface-flux parameterizations (figure $3 \mathrm{e}$ ).

\subsection{Sensitivity experiments with $P B L$ and convection schemes}

Figure 3(f) gives the tracks of the six different combinations of PBL and convection parameterization schemes on resolution 9-km grid with movable nesting compared to IMD. The combination of MYJ PBL scheme with KF convection scheme has presented a predicted track with better quality than the other combinations. The model predicted the first landfall over Oman with position error $10 \mathrm{~km}$ and time error $6 \mathrm{hr}$ (delay) and the second landfall of Gonu over Iran with position error $30 \mathrm{~km}$ and time error $21 \mathrm{hr}$ (delay) for MYJ-KF combination. The results conveyed that BMJ convection scheme meaningfully predicted track accuracy. Osuri et al. (2012) also presented that convection schemes strongly affect the cyclone tracks; 


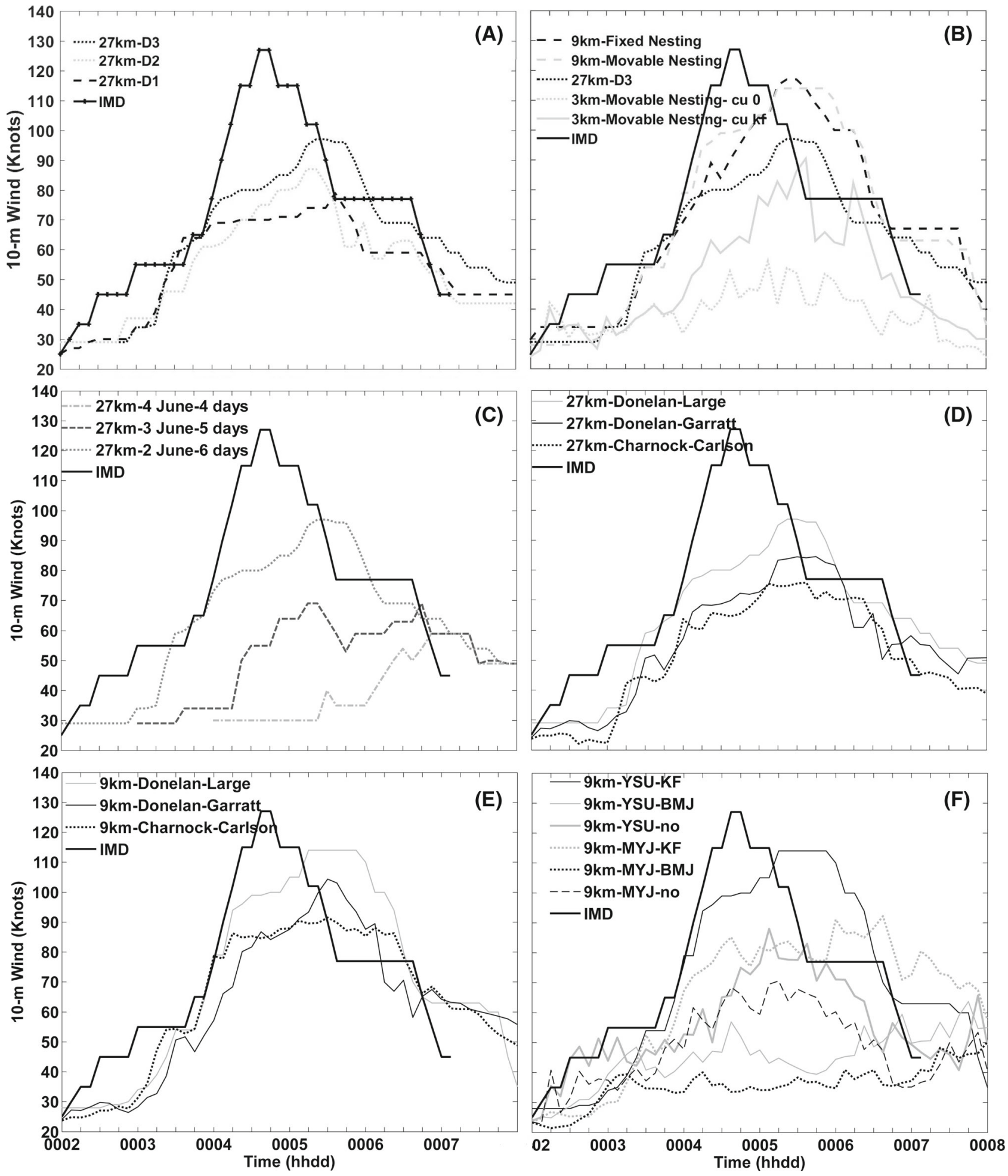

Figure 4. Same as figure 3, but for simulated maximum 10-m wind.

however, there was no salient difference between the simulations of KF and BMJ convections. With a bit of leniency, the simulated track by YSU-KF combination placed in the next level. This combination had the best performance in the simulations of Osuri et al. (2012). The simulated track by
YSU-BMJ and MYJ-BMJ combinations were almost consistent with IMD in the first 3 days. After that, swerve amazingly from the IMD track and passes so far from the coast of Oman. Figures $4(\mathrm{f})$ and $5(\mathrm{f})$ give the simulated intensity of the six different combinations of PBL and 


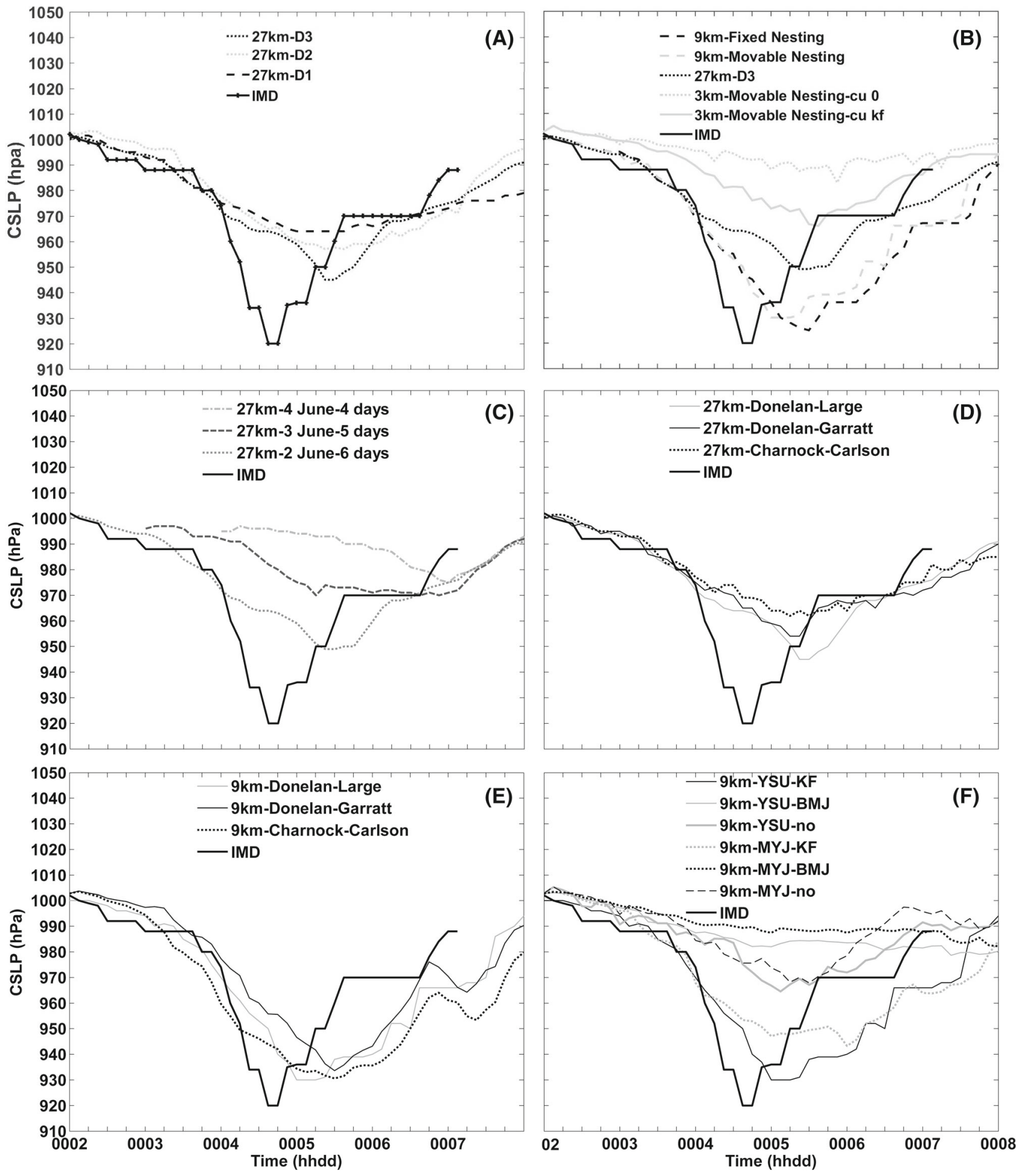

Figure 5. Same as figure 4, but for simulated minimum sea level pressure.

convection parameterization schemes compared to IMD for maximum $10-\mathrm{m}$ wind and minimum sea level pressure, respectively. The YSU-KF in prediction of cyclone peak intensity had exhibited a better performance compared with other combinations; however, the MYJ-KF combination placed in the next level of performance in the predicted track (see figure 3f) and had not an acceptable performance in prediction of intensity of the cyclone (see figures $4 \mathrm{f}$ and $5 \mathrm{f}$ ). The other combinations did not provide good simulated intensity results. 
Table 3. Errors in simulated track near shoreline of Iran, Oman, the intensity at peak time, and time errors in reaching cyclone to these shorelines for each sensitivity experiments.

\begin{tabular}{|c|c|c|c|c|c|c|c|}
\hline \multirow[b]{2}{*}{$\begin{array}{l}\text { Names of } \\
\text { experiments }\end{array}$} & \multicolumn{2}{|c|}{ Iran shoreline } & \multicolumn{2}{|c|}{ Oman shoreline } & \multicolumn{3}{|c|}{ Peak intensity } \\
\hline & $\begin{array}{l}\text { Position } \\
\text { error } \\
(\mathrm{km})\end{array}$ & $\begin{array}{r}\text { Time } \\
\text { error } \\
(\mathrm{hr})\end{array}$ & $\begin{array}{l}\text { Position } \\
\text { error } \\
(\mathrm{km})\end{array}$ & $\begin{array}{l}\text { Time } \\
\text { error } \\
(\mathrm{hr})\end{array}$ & $\begin{array}{c}\text { CSLP } \\
\text { error }(\mathrm{hPa})\end{array}$ & $\begin{array}{l}\text { Max wind } \\
10 \text { m error } \\
(\text { knot })\end{array}$ & $\begin{array}{c}\text { Time error } \\
\text { (hr) }\end{array}$ \\
\hline 27 km-D1 & NO L.F & - & 0 & -24 & -45 & +50 & -18 \\
\hline 27 km-D2 & NO L.F & - & 90 & -30 & -35 & +40 & -15 \\
\hline $27 \mathrm{~km}-\mathrm{D} 3$ & 90 & -15 & 9 & -15 & -25 & +30 & -15 \\
\hline $9 \mathrm{~km}$-fixed nesting & 0 & -21 & 100 & 0 & -5 & +8 & -12 \\
\hline 9 km-movable nesting & 30 & -21 & 120 & -15 & -10 & +10 & -9 \\
\hline 3 km-movable nesting-cu 0 & NO L.F & - & NO L.F & - & - & - & - \\
\hline 3 km-movable nesting-cu 1 & NO L.F & - & 110 & -30 & -50 & 33 & 30 \\
\hline 27 km-3 June-5 days & 110 & -15 & NO L.F & - & - & - & - \\
\hline 27 km-4 June-4 days & 120 & -15 & NO L.F & - & - & - & - \\
\hline 27 km-Charnock-Carlson and Boland & 90 & -15 & 9 & -15 & -45 & +50 & -12 \\
\hline 27 km-Donelan-Large and Pond & 90 & -15 & 9 & -15 & -25 & +30 & -15 \\
\hline 27 km-Donelan-Garratt & 10 & -15 & NO L.F & - & -35 & 38 & -9 \\
\hline $9 \mathrm{~km}$-Charnock-Carlson and Boland & 30 & -21 & 120 & -15 & -10 & +35 & -9 \\
\hline $9 \mathrm{~km}$-Donelan-Large and Pond & 30 & -21 & 120 & -15 & -10 & +10 & -9 \\
\hline 9 km-Donelan-Garratt & 30 & -21 & 120 & -15 & -15 & +20 & -9 \\
\hline 9 km-YSU-BMJ & NO L.F & - & NO L.F & - & - & - & - \\
\hline 9 km-YSU-KF & 30 & -21 & 120 & -15 & -10 & +10 & -9 \\
\hline 9 km-YSU-no & 30 & -21 & 130 & -12 & -45 & +45 & -18 \\
\hline 9 km-MYJ-BMJ & NO L.F & - & NO L.F & - & - & - & - \\
\hline 9 km-MYJ-KF & 30 & -21 & 10 & -6 & -25 & +35 & -30 \\
\hline 9 km-MYJ-no & NO L.F & - & 120 & -15 & -48 & +55 & -18 \\
\hline
\end{tabular}

\subsection{Review of sensitivity experiments performance}

In order to present a summary of performed simulations, table 3 shows errors in simulated track near the shore of Iran-Oman and intensity at peak point and also time errors in reaching cyclone to these points for sensitivity to domain design, starting time and horizontal resolution, surface-flux parameterizations, cumulus convection and $\mathrm{PBL}$ parameterization schemes, respectively.

\section{Conclusion}

According to the numerical-experimental results and analyses in this study, the simulated track and intensity of a supertropical cyclone could show a significant sensitivity to the domain coverage, horizontal resolution, initial condition, ocean-atmosphere surface flux parameterizations (momentum, heat and moisture), planetary boundary layer (PBL) and cumulus convection physical parameterizations. Simulations demonstrated that selective domains that was extended more to the east (D3 with $27 \mathrm{~km}$ resolution) with the initial condition before intense deepening of low pressure, or in other words, when the central pressure turned around $1000 \mathrm{hPa}$, it presented satisfactory cyclone track and for intensity at reaching time to the coast of Oman and Iran had acceptable performance. Improving simulations with the initial condition before the rapid deepening of low pressure, was consistent with the result of Kanase and Salvekar (2011). When the simulation initialized after this time, the model is not able to simulate correctly the rapid intensification and thermodynamic phenomena at the future time. In other words, model needs enough time until surface fluxes of heat and moisture penetrate deeply into the troposphere in order to simulate tropical cyclone intensification and this subject was clearly observed in this study. Conducting fixed and movable nesting (9-km resolution) separately within the coarse domain, though revealing significantly improved simulated intensity accuracy, significantly reduced the quality of the simulated track. Simulated tracks in lower horizontal resolution $(27 \mathrm{~km})$ were better than higher horizontal resolution $(9 \mathrm{~km})$ that confirmed the result of Goerss (2006). Goerss (2006) had expressed that high resolution is not a requirement for 
improved track prediction. Increasing horizontal resolution to $3 \mathrm{~km}$ incredibly reduced the simulated intensity accuracy, even weaker than $27 \mathrm{~km}$ resolution. This requires further studies in future. This result is uncommonly contrary to results of Davis et al. (2008, 2010) and should be evaluated with complemental methods for TC simulation in this region. It was also shown that the fixed nesting has better performance than movable nesting. However, it is estimated that the cost of implementing fixed nesting will be considerably more than for movable nesting, but this nesting method presented better track and intensity results in this study. It can be said that the movable nesting techniques and their performance significantly developed and improved in recent years (e.g., Fierro et al. 2009; Tallapragada et al. 2014 and ARW User's Guides 2017), but in practice, the movable nesting with respect to the less CPU processing has some advantages. It is applicable to use the results of preliminary simulations to predict the track and the results of nesting simulations to predict intensity.

A significant sensitivity of Gonu simulated intensity to the surface-flux parameterizations was also observed. The experiment with Donelan parameterization for momentum exchange and LargePond parameterization for enthalpy were found to be more efficient. Authors concluded that the effects of $C_{d}$ is more than that of $C_{k}$ in predicting of TC intensity. There are different formulations for $C_{d}$. Thus, based on the results of this study and Davis et al. (2008), for better considering drag coupling with a wave model can improve the results. Also, the results showed that simulated track could not be more sensitive to the surface-flux parameterizations. The difference in drag between the two drag formulations through Donelan and Charnock scheme is relatively smaller than the reality.

It was found that the AHW configurations with MYJ-PBL and KF convection schemes for track prediction and YUS-PBL and KF convection schemes for intensity prediction were satisfactory. The KF scheme produced more realistic intensity and track positions with relatively higher convective warming and stronger vertical motions in the upper troposphere relative to the other cumulus schemes, which may be due to the triggering of convection based on buoyancy in the case of the KF scheme (Srinivas et al. 2013). Larger eddies in YUS-PBL quickly transport surface heat to higher altitude and entrain higher potential temperatures above the PBL incorporating a countergradient correction term into downgradient-diffusion-caused increased intensity than MYJ-PBL. It can be mentioned that the sensitivity results of simulations to the convection and PBL parameterization schemes in this study is almost consistent with Osuri et al. (2012) study.

The results implicitly indicated that each particular forecast aspect of TC (e.g. track, intensity, etc.) in general will require its own special design.

\section{Acknowledgements}

We would like to acknowledge the generous help of India Meteorological Department and Iran Meteorological Organization (IRIMO), for providing essential data. We also thank the anonymous reviewers for their valuable comments that improved the quality of manuscript. The funding was provided by the University of Hormozgan (Bandar Abbas, Iran).

\section{References}

Advanced Research WRF (ARW) Modeling System User's Guides, Version 3 (2017) http://www2.mmm.ucar.edu/ wrf/users/docs/user_guide_V3/contents.html

Anthes R A 1982 Tropical cyclones: Their evolution, structure and effects; Meteor. Mono. Am. Meteor. Soc., 208p.

Betts A K and Miller M J 1986 A new convective adjustment scheme. Part II: Single column tests using GATE wave, BOMEX, ATEX, and Arctic air-mass data sets; Quart. J. Roy. Meteorol. Soc. 112 693-709.

Black P G, D'Asaro E A, Drennan W M, French J R, Niiler P P, Sanford T B, Terrill E J, Walsh E J and Zhang J A 2007 Air-sea exchange in hurricanes: Synthesis of observations from the coupled boundary layer air-sea transfer experiment; Bull. Am. Meteorol. Soc. 88 357-374.

Braun S A and Tao W K 2000 Sensitivity of high-resolution simulations of hurricane Bob (1991) to planetary boundary layer parameterizations; Mon. Wea. Rev. $1283941-$ 3961.

Carlson T N and Boland F E 1978 Analysis of urban-rural canopy using a surface heat flux/temperature model; $J$. Appl. Meteorol. 17 998-1013.

Charnock H 1955 Wind stress on a water surface; Quart. J. Roy. Meteorol. Soc. 81 639-640.

Chen S S, Price J F, Zhao W, Donelan M A and Walsh E J 2007 The CBLAST-Hurricane Program and the nextgeneration fully coupled atmosphere-wave-ocean models for hurricane research and prediction; Bull. Am. Meteorol. Soc. 88 311-317.

Chen S, Qian Y K and Peng S 2015 Effects of various combinations of boundary layer schemes and microphysics schemes on the track forecasts of tropical cyclones over the South China Sea; Nat. Hazards 78 61-74. 
Davis C and Bosart F L 2001 Numerical simulations of the genesis of hurricane Diana (1984). Part II: Sensitivity of track and intensity prediction; Mon. Mon. Wea. Rev. 130 1100-1124.

Davis C, Wang W, Dudhia J and Torn R 2010 Does increased horizontal resolution improve hurricane wind forecasts?; Wea. Forecasting 25 1826-1841.

Davis C, Wang W, Chen S S, Chen Y, Corbosiero K, DeMaria M, Dudhia J, Holland G, Klemp J, Michalakes J, Reeves H, Rotunno R, Snyder C and Xiao Q 2008 Prediction of land falling hurricanes with the advanced hurricane WRF model; Mon. Wea. Rev. 136 1990-2005.

Deshpande M, Pattnaik S, Salvekar P S 2010 Impact of physical parameterization schemes on numerical simulation of super cyclone Gonu; Nat. Hazards 55 211231.

Donelan M, Haus B, Reul N, Plant W, Stiassnie M, Graber H, Brown O and Saltzman E 2004 On the limiting aerodynamic roughness of the ocean in very strong winds; Geophys. Res. Lett. 31 L18306.

Dudhia J 1989 Numerical study of convection observed during the winter monsoon experiment using a mesoscale two-dimensional model; J. Atmos. Sci. 46 3077-3107.

Emanuel K A 1995 Sensitivity of tropical cyclones to surface exchange coefficients and a revised steady-state model incorporating eye dynamics; J. Atmos. Sci. 52 3969-3976.

Fierro A O, Rogers R F and Marks F D 2009 The impact of horizontal grid spacing on the microphysical and kinematic structures of strong tropical cyclones simulated with the WRF-ARW Model; Mon. Wea. Rev. 137 3717-3743.

Frank W M and George S Y 2007 The interannual variability of tropical cyclones; Mon. Wea. Rev. 135 3587-3598.

Garratt J R 1992 The Atmospheric Boundary Layer; Cambridge University Press, Cambridge.

Goerss J S 2006 Prediction of tropical cyclone track forecast error for hurricanes Katrina, Rita, and Wilma; Preprints, 27th Conf. on Hurricanes and Tropical Meteorology, Am. Meteor. Soc., Monterey, CA.

Gopalakrishnan S, Liu Q, Marchok T, Sheinin D, Surgi N, Tuleya R, Yablonski R and Zhang X 2010 Hurricane Weather Research and Forecasting (HWRF) model scientific documentation.

Hong S Y, Dudhia J and Chen S H 2004 A revised approach to ice microphysical processes for the bulk parameterization of cloud sand precipitation; Mon. Wea. Rev. 132 $103-120$

Hong S Y, Noh Y and Dudhia J 2006 A new vertical diffusion package with an explicit treatment of entrainment processes; Mon. Wea. Rev. 134 2318-2341.

IMD 2008 Track of storm and depressions over the Indian Seas during 1891-2008; Cyclone e-Atlas published by IMD, http://www.imd.gov.in/section/nhac/dynamic/.

Janjic Z I 1990 The step-mountain coordinate: Physics package; Mon. Wea. Rev. 118 1429-1443.

Janjic Z I 1994 The step-mountain eta coordinate model: Further developments of the convection, viscous sublayer and turbulence closure schemes; Mon. Wea. Rev. 122 927-945.

Janjic Z I 2003 A nonhydrostatic model based on a new approach; Meteor. Atmos. Phys. 82 271-285.

Kain J S 2004 The Kain-Fritsch convective parameterization: An update; J. Appl. Meteorol. 43 170-181.
Kain J S and Fritsch J M 1993 Convective parameterization for mesoscale models: The Kain-Fritsch scheme. The representation of cumulus convection in numerical models; Meteorol. Monogr. 46 165-170.

Kanase R D and Salvekar P S 2011 Numerical simulation of severe cyclonic storm LAILA (2010): Sensitivity to initial condition \& cumulus parameterization scheme; Proc. Disaster Risk Vulnerablity. Conf., Germany 1 165-170.

Krishnamurti T N 2005 The hurricane intensity issue; Mon. Wea. Rev. 133 1886-1912.

Kumar A, Done J, Dudhia J and Niyogi D 2011 Simulations of cyclone Sidr in the Bay of Bengal with a high-resolution model: Sensitivity to large-scale boundary forcing; Meteorol. Atmos. Phys. 114 123-137.

Large W G and Pond S 1981 Open ocean momentum flux measurements in moderate to strong winds; J. Phys. Oceanogr. 11 324-336.

Mandal M, Mohanty U C and Raman S 2004 A study on the impact of parameterization of physical processes on prediction of tropical cyclones over the Bay of Bengal with NCAR/PSU mesoscale model; Nat. Hazards $\mathbf{3 1}$ 391-414.

Mellor G L and Yamada T 1982 Development of a turbulence closure model for geophysical fluid problems; Rev. Geophys. Space Phys. 20 851-875.

Mlawer E, Taubman S, Brown P, Lacono M and Clough S 1997 Radiative transfer for inhomogeneous atmosphere: RRTM, a validated correlated-k model for the long-wave; J. Geophys. Res. 102 16663-16682.

Mohandas S and Ashrit R 2013 Sensitivity of different convective parameterization schemes on tropical cyclone prediction using a mesoscale model; Nat. Hazards 73213 235.

Mohanty U C and Gupta A 1997 Deterministic methods for prediction of tropical cyclone tracks; Mausam 48 257-272.

Noh Y, Cheon W, Hong S and Raasch S 2003 Improvement of the k-profile model for the planetary boundary layer based on large eddy simulation data; Bound. Layer Meteorol. 107 401-427.

Nolan D S, Stern D P and Zhange J A 2009 Evaluation of planetary boundary layer parameterizations in tropical cyclones by comparison of in situ observations and highresolution simulations of hurricane Isabel (2003). Part II: Inner-core boundary layer and eyewall structure; Mon. Wea. Rev. 137 3675-3698.

Osuri K K, Mohanty U C, Routray A, Mohapatra M and Niyogi D 2013 Real-time track prediction of tropical cyclones over the North Indian Ocean using the ARW Model; J. Appl. Meteorol. Climatol. 52 2476-2492.

Osuri K K, Mohanty U C, Routray A, Kulkarni M A and Mohapatra M 2012 Customization of WRF-ARW model with physical parameterization schemes for the simulation of tropical cyclones over North Indian Ocean; Nat. Hazards 63 1337-1359.

Pattanayak S and Mohanty U 2008 A comparative study on performance of MM5 and WRF models in simulation of tropical cyclones over Indian seas; Curr. Sci. 95 923-936.

Pollard R T, Rhines P B and Thompson R O R Y 1973 The deepening of the wind-mixed layer; Geophys. Astrophys. Fluid. Dyn. 4 381-404.

Rao G V and Bhaskar Rao D V 2003 A review of some observed mesoscale characteristics of tropical cyclones and 
some preliminary numerical simulations of their kinematic features; Proc. Indian Nat. Sci. Acad. 69 523-541.

Schwartz C S, Kain J S, Weiss S J, Xue M, Bright D R, Kong F, Thomas K W, Levit J J and Coniglio M C 2009 Next-day convection-allowing WRF model guidance: A second look at 2-km versus 4-km grid spacing; Mon. Wea. Rev. 137 3351-3372.

Srinivas C V, Bhaskar Rao D V, Vesubabu V, Baskaran R and Venkatesan R 2013 Tropical cyclone predictions over the Bay of Bengal using the high-resolution advanced research weather research and forecasting (ARW); Quart. J. Roy. Meteor. Soc. 139 1810-1825.

Tallapragada V, Kieu V, Kwon Y, Trahan S, Liu Q, Zhang Z and Kwon I H 2014 Evaluation of storm structure from the operational HWRF during 2012 Implementation; Mon. Wea. Rev. 142 4308-4325.

Tallapragada V, Bernardet L, Biswas M K, Gopalakrishnan M, Kwon Y, Liu Q, Marchok T, Sheinin D, Tong M, Trahan S, Tuleya R, Yablonsky R and Zhang X 2014 Hurricane Weather Research and Forecasting (HWRF) Model: 2014 Scientific Documentation.

Torn R D 2016 Evaluation of atmosphere and ocean initial condition uncertainty and stochastic exchange coefficients on ensemble tropical cyclone intensity forecasts; Mon. Wea. Rev. 144 3487-3506.

WMO 2014 Tropical cyclone operational plan for the Bay of Bengal and the Arabian Sea; http://www.wmo.int/pages/ prog/www/tcp/operational-plans.html.

Corresponding editor: KAVIRAJAN RAJENDRAN 